\title{
Reconsideration of Augmentation Strategies in Electroconvulsive Therapy: Effects of the Concurrent Use of a Reduced Dose of Propofol with Divided Supplemental Remifentanil and Moderate Hyperventilation on Electroconvulsive Therapy-Induced Seizure Production and Adverse Events
}

\author{
Kohki Nishikawa ${ }^{1 *}$, Michiaki Yamakage ${ }^{2}$ \\ ${ }^{1}$ Department of Anesthesia, Muroran City General Hospital, Muroran, Japan \\ ${ }^{2}$ Department of Anesthesiology, Sapporo Medical University School of Medicine, Sapporo, Japan \\ Email: ${ }^{*}$ murohosp082@kujiran.jp
}

Received 9 October 2015; accepted 26 October 2015; published 29 October 2015

Copyright (C) 2015 by authors and Scientific Research Publishing Inc.

This work is licensed under the Creative Commons Attribution International License (CC BY).

http://creativecommons.org/licenses/by/4.0/

(c) (i) Open Access

\begin{abstract}
Background: Although several treatment strategies to enhance the efficacy of electroconvulsive therapy (ECT) have been discussed, there have been no reports on the combined use of these treatments. The purpose of this study was to evaluate the efficacy and safety of concurrent use of moderate hyperventilation and a reduced dose of propofol combined with divided remifentanil in ECT practice. Methods: Sixty patients scheduled to receive a total of 300 ECT treatments were randomly assigned to have the three interventions: a standard dose $(1 \mathrm{mg} / \mathrm{kg}$ ) of propofol (group $\mathrm{P} / \mathrm{N}$ ); a standard dose of propofol and moderate hyperventilation with end-tidal pressure of carbon dioxide $\left(\mathrm{ETCO}_{2}\right)$ of $30-35 \mathrm{mmHg}($ group $\mathrm{P} / \mathrm{H})$; and a reduced dose $(0.5 \mathrm{mg} / \mathrm{kg})$ of propofol with divided supplemental remifentanil and moderate hyperventilation (group RP/H). Patients in group $\mathrm{RP} / \mathrm{H}$ received remifentanil $1 \mu \mathrm{g} / \mathrm{kg}$ followed by propofol $0.5 \mathrm{mg} / \mathrm{kg}$ for unconsciousness and thereafter remifentanil $1 \mu \mathrm{g} / \mathrm{kg}$ immediately before the ECT stimulus. Results: Patients in
\end{abstract}

\footnotetext{
${ }^{*}$ Corresponding author.
}

How to cite this paper: Nishikawa, K. and Yamakage, M. (2015) Reconsideration of Augmentation Strategies in Electroconvulsive Therapy: Effects of the Concurrent Use of a Reduced Dose of Propofol with Divided Supplemental Remifentanil and Moderate Hyperventilation on Electroconvulsive Therapy-Induced Seizure Production and Adverse Events. Open Journal of Anesthesiology, 5, 219-226. http://dx.doi.org/10.4236/ojanes.2015.510040 
group RP/H showed significantly longer durations of electroencephalographic (EEG) seizures in the early phase of ECT course $(P<0.01$ and 0.05$)$ and lower electrical stimulus in the late phase of ECT course $(P<0.05$ in each) than those in groups $P / N$ and $P / H$, respectively. Conclusions: The use of a reduced dose of propofol combined with divided supplemental remifentanil under moderate hyperventilation during ECT can offer advantages over the use of a standard dose of propofol with or without moderate hyperventilation in terms of more seizure augmentation and/or lower electrical stimulus.

\section{Keywords}

Electroconvulsive Therapy, Moderate Hyperventilation, Reduced Dose of Propofol, Seizure Duration, Electrical Stimulus Intensity

\section{Introduction}

Electroconvulsive therapy (ECT) has been used as a highly efficacious treatment of mood and psychotic disorders, and the duration of ECT-induced seizure activity has been extensively studied as a possible marker for clinical efficacy. Although the effect of generalized seizure duration on the clinical outcome remains unclear, no seizure or a brief seizure duration is considered to be less effective ECT [1]. Advanced age [2], increment of ECT treatments [3], and the use of hypnotic agents with anticonvulsant properties [4] [5], have been reported to increase seizure thresholds, and high initial seizure thresholds have been shown to result in shorter seizure duration. Augmentation strategies for enhancing seizure production may therefore be required for patients with high seizure thresholds and with shortened seizures or inability to elicit seizures.

For augmentation of therapeutic seizures in ECT [6], several procedures, including hyperventilation [7]-[9] and the use of remifentanil [10]-[14] or ketamine [15] [16], have been reported to have varying degrees of success. The American Psychiatric Association [1] first recommends restimulation at higher intensities for patients with suboptimal seizure induction, and next suggests hyperventilation in the management of patients with inadequate seizure induction after restimulation. Severely high stimulus intensities and/or a markedly high level of hyperventilation for patients refractory to optimal seizure production in the maximal ECT settings may however contribute to the severe cognitive dysfunction and/or cerebral hypoxia and myocardial ischemia induced by cerebral and coronary vasoconstriction.

On the other hand, we expected that concomitant use of some augmentation treatments for strategies with less adverse effects for enhancing outcomes would be appropriate. To the best of our knowledge, however, there have been no reports on this combined technique.

The present study was therefore conducted to evaluate whether concomitant application of a reduced dose of propofol combined with divided remifentanil supplementation and moderate hyperventilation for ECT procedures led to greater seizure augmentation and/or fewer side effects compared with a standard use of propofol with or without moderate hyperventilation.

\section{Materials and Methods}

After obtaining IRB approval at Muroran City General Hospital and written, informed consent from each patient, patients with a variety of psychiatric conditions were enrolled in a prospective, randomized, controlled trial. Exclusion criteria were age younger than 20 years or older than 80 years, myocardial infarction in the previous 6 months, coronary artery disease, atrial fibrillation or flutter, heart block, uncontrollable hypertension, chronic respiratory disease, cerebrovascular diseases, and drug allergy. ECT treatments were given to all patients 3 times per week with 2-day intervals. One sequential ECT treatment consisted of 5 to 10 ECT treatment sessions. None of the patients was premedicated. The patients were assigned to the following three groups $(n=20$ each) in a stratified, randomized order: 1) a group in which patients had propofol alone for anesthetic induction and received normoventilation [end-tidal carbon dioxide partial pressure $\left(\mathrm{ETCO}_{2}\right)$ of 40 - $45 \mathrm{mmHg}$ before ECT (group P/N); 2) a group in which patients had propofol alone and received moderate hyperventilation $\left(\mathrm{ETCO}_{2}\right.$ of 30 - $35 \mathrm{mmHg}$ ) before ECT (group P/H); and 3) a group in which patients had a reduced dose of propofol with 
divided infusion of remifentanil and received moderate hyperventilation $\left(\mathrm{ETCO}_{2}\right.$ of 30 - $35 \mathrm{mmHg}$ ) before ECT (group RP/H).

Patients in groups $\mathrm{P} / \mathrm{N}$ and $\mathrm{P} / \mathrm{H}$ received propofol at $1 \mathrm{mg} / \mathrm{kg}$ over $20 \mathrm{sec}$, and patients in group RP/H had remifentanil at $1 \mu \mathrm{g} / \mathrm{kg}$ over $60 \mathrm{sec}$, followed by propofol at $0.5 \mathrm{mg} / \mathrm{kg}$ over $10 \mathrm{sec}$ to induce unconsciousness. On loss of consciousness, a blood pressure cuff was inflated on the right or left leg, and $1 \mathrm{mg} / \mathrm{kg}$ succinylcholine was administered intravenously. Patients in group RP/H were thereafter given remifentanil at $1 \mu \mathrm{g} / \mathrm{kg}$ over 60 sec again immediately before the ECTstimulus. All medication with remifentanil was prepared in a $10-\mathrm{mL}$ syringe diluted with $0.9 \%$ normal saline. From after succinylcholine infusion to immediately before the ECT stimulus, patients in group $\mathrm{P} / \mathrm{N}$ were manually ventilated using a facemask with $100 \%$ oxygen with normoventilation being performed, and patients in groups $\mathrm{P} / \mathrm{H}$ and $\mathrm{RP} / \mathrm{H}$ were ventilated with hyperventilation performed. After resolution of muscle fasciculation and manual ventilation over 120 sec, a suprathreshold electrical stimulus was delivered via bifrontotemporal electrodes with a Thymatron DGX device (Somatics, Palo Alto, CA, USA) by a psychiatrist. The magnitude of stimulus intensity provided by ECT was predetermined by age for each patient's first ECT ("half-age" stimulation strategy) [17]. The pulse width was 1.0 millisecond, and the frequency was $70 \mathrm{~Hz}$. When an inadequate seizure appeared with the half-age stimulation setting, stimulus intensity was determined by the stepwise increase method [18] from the next treatment.

Systolic blood pressure (SBP), mean arterial blood pressure (MAP), heart rate (HR), and oxygen saturation were recorded before and after anesthesia and at $0,1,2,3,4$, and 5 min after the ECT stimulus. Baseline MAP and HR were determined from the average of three consecutive readings. The rate-pressure product (RPP) was calculated from SBP and HR in each ECT session. The durations of motor and electroencephalographic (EEG) seizure activities were recorded using electromyographic (EMG) and EEG monitors attached to the ECT device as the times from the electrical stimulus to cessation of tonic-clonic motor activity in the isolated foot and to postictal EEG suppression, respectively. Times from the ECT stimulus to spontaneous breathing and to response to a simple verbal command (emergence time) were assessed. Adequate seizure duration was defined as an EEG seizure duration of more than $25 \mathrm{sec}$ or motor seizure duration of more than $20 \mathrm{sec}$ [18]. Hypotension and bradycardia during ECT were defined as a decrease of more than 30\% from baseline MAP and HR of less than 45 beats per minute (bpm), respectively. Data were collected during the first 5 ECT sessions for all patients.

A power analysis was performed on the basis of the previously reported $39 \%-48 \%$ prolongation in the duration of motor seizure activity with remifentanil [14]-[19], and results of the analysis suggested that a sample size of 18 - 20 patients in each group would have a 90\% power to detect a 39\% - 48\% difference in motor seizure duration with Type I error probability of 0.05 . Data are presented as means \pm SD andnumbers $(n)$. Patients' characteristics and recovery profiles were compared using single-factor analysis of variance (ANOVA) with post hoc tests. Statistical intergroup comparisons of electrical stimulus intensity, EEG, and motor seizure durations and hemodynamic data in the series of five sessions were performed using repeated-measures ANOVA followed by Student's $t$-test. The percentages of ECT sessions with EEG seizure duration $>25$ sec, motor seizure duration >20 sec, and peak RPP values > 20,000 were compared using the chi-square test for independence. A probability value less than 0.05 was considered significant.

\section{Results}

Sixty patients were recruited for the study, and a total of 300 ECT treatment sessions were evaluated. The patients suffered from major depression (12 patients) or schizophrenia (48 patients) refractory to drug therapy. Groups $\mathrm{P} / \mathrm{N}, \mathrm{P} / \mathrm{H}$, and $\mathrm{RP} / \mathrm{H}$ were comparable with respect to age, weight, sex distribution, and percentage of patients with a history of hypertension (Table 1 ).

Electrical stimulus intensities by session number for the three groups are presented in Figure 1. Although the stimulus intensities required increased gradually with session number in all three groups, no significant difference in the stimulus doses in the first and second ECT sessions was found among the three groups. Stimulus intensities in the third $(P<0.05)$, fourth $(P<0.05)$, and fifth $(P<0.01)$ ECT sessions were however significantly lower in group $\mathrm{RP} / \mathrm{H}$ than in group $\mathrm{P} / \mathrm{N}$. In addition, patients in group $\mathrm{RP} / \mathrm{H}$ had significantly lower intensities than those in group $\mathrm{P} / \mathrm{H}$ in the fifth ECT session $(P<0.05)$.

Mean EEG seizure duration was significantly longer in patients in group $\mathrm{RP} / \mathrm{H}$ than in group $\mathrm{P} / \mathrm{N}$ in the first and second ECT sessions $(P<0.01)$. Patients in group RP/H also showed a significantly longer duration of EEG seizure activity than those in group $\mathrm{P} / \mathrm{H}$ in the second session $(P<0.05)$. A significantly longer prolongation of EEG seizures was also found in patients in group $\mathrm{P} / \mathrm{H}$ than in those in group $\mathrm{P} / \mathrm{N}(P<0.05)$ (Figure 2). The 
Table 1. Demographic data of the three groups.

\begin{tabular}{cccc}
\hline & P/N $(\mathbf{n}=\mathbf{2 0})$ & $\mathbf{P} / \mathbf{H} \mathbf{( n = 2 0 )}$ & $\mathbf{R P / H}(\mathbf{n}=\mathbf{2 0})$ \\
\hline Sex (M/F) & $12 / 8$ & $11 / 9$ & $13 / 7$ \\
Age (yr) & $59.9 \pm 8.6$ & $62.6 \pm 9.7$ & $58.0 \pm 11.2$ \\
Weight (kg) & $56.8 \pm 10.7$ & $57.3 \pm 8.2$ & $52.8 \pm 16.2$ \\
Disease (S/D) & $14 / 6$ & $13 / 7$ & $15 / 5$ \\
HT/NT & $9 / 11$ & $10 / 10$ & $11 / 9$ \\
\hline
\end{tabular}

S: Schizophrenia, D: depression, HT: Hypertension, NT: Normotension; Values are expressed as means \pm SD or $n$.

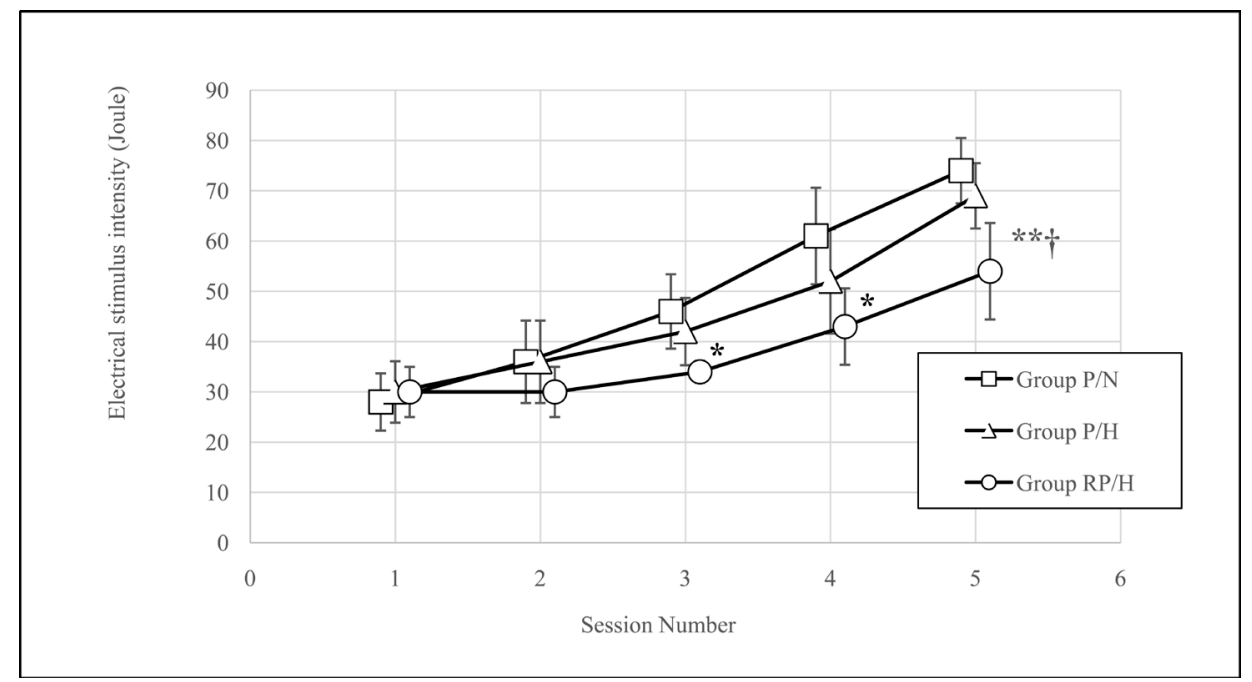

${ }^{*} \mathrm{P}<0.05$ in group $\mathrm{RP} / \mathrm{H}$ compared with group $\mathrm{P} / \mathrm{N}$ in the third and fourth ECT sessions. ${ }^{* *} \mathrm{P}<0.01$ in group RP/H compared with group $\mathrm{P} / \mathrm{N}$ in the fifth ECT session. ${ }^{\dagger} P<0.05$ in group RP/H compared with group $\mathrm{P} / \mathrm{H}$ in the fifth ECT session. ECT: electroconvulsive therapy, Group P/N or $\mathrm{P} / \mathrm{H}$ : normoventilated or hyperventilated group receiving a standard dose of propofol, Group RP/H: hyperventilated group receiving a reduced dose of propofol with remifentanil.

Figure 1. Electrical stimulus intensities by session number in the three groups. Values are expressed as mean \pm SD.

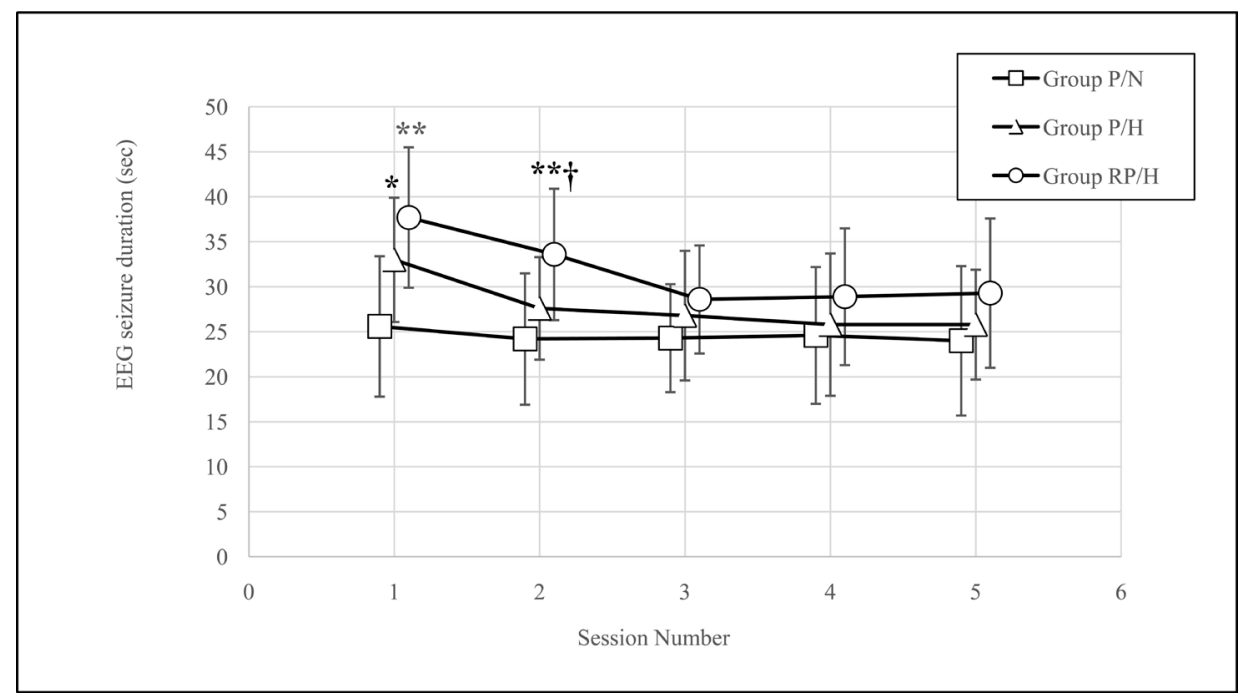

${ }^{* *} \mathrm{P}<0.01$ in group $\mathrm{RP} / \mathrm{H}$ compared with group $\mathrm{P} / \mathrm{N}$ in the first and second ECT sessions. ${ }^{*} \mathrm{P}<0.05$ in group $\mathrm{P} / \mathrm{H}$ compared with group $\mathrm{P} / \mathrm{N}$ in the first ECT session. ${ }^{\dagger} P<0.05$ in group RP/H compared with group P/H in the second ECT session. EEG: electroencephalogram, ECT: electroconvulsive therapy, Group $\mathrm{P} / \mathrm{N}$ or $\mathrm{P} / \mathrm{H}$ : normoventilated or hyperventilated group receiving a standard dose of propofol, Group RP/H: hyperventilated group receiving a reduced dose of propofol with remifentanil.

Figure 2. EEG seizure durations by session number in the three groups. Values are expressed as mean \pm SD. 
duration of motor seizures was significantly longer in patients in group $\mathrm{RP} / \mathrm{H}$ than in those in group $\mathrm{P} / \mathrm{N}$ only in the first ECT session $(P<0.05)$ (Figure 3). The percentage of sessions with EEG seizure duration of longer than $25 \mathrm{sec}$ was significantly larger in group RP/H (88\%) than in group P/N (60\%) in a total of 100 sessions in each group $(P<0.05)$. Motor seizure durations of longer than 20 sec were seen in $86 \%$ of a total of 100 sessions in group $\mathrm{RP} / \mathrm{H}$ and in $75 \%$ of those in group $\mathrm{P} / \mathrm{N}$, but the difference was not significant (Table 2). The time to spontaneous breathing and awakening time were both significantly increased in patients in group $\mathrm{RP} / \mathrm{H}$ than in those in groups $\mathrm{P} / \mathrm{N}$ and $\mathrm{P} / \mathrm{H}(P<0.01)$ (Table 2). Only one patient in group $\mathrm{P} / \mathrm{N}$ developed emergence agitation in this study.

Regarding hemodynamic responses after the ECT stimulus, the percentage increases from post-anesthetic values to peak post-ictal values of MAP $(\triangle \mathrm{MAP})$ and $(\triangle \mathrm{HR})$ tended to be larger in group $\mathrm{RP} / \mathrm{H}$ than in groups $\mathrm{P} / \mathrm{N}$ and $\mathrm{P} / \mathrm{H}$ in each ECT session, but the differences were not significant (Table 3). Doses of rescue intravenous ephedrine and verapamil were also not significantly different among the three groups (Table 2). Maximal values of RPP in each ECT session (Table 4) and the percentages of ECT sessions with peak RPP of greater than 20,000 (Table 2) were both similar among the three groups. None of the patients in the three groups developed arrhythmias or showed ECG signs of myocardial ischemia.

\section{Discussion}

The present study showed that the concomitant use of a reduced dose of propofol with divided remifentanil supplementation at $2 \mu \mathrm{g} / \mathrm{kg}$ and moderate hyperventilation with $\mathrm{ETCO}_{2}$ of $30-35 \mathrm{mmHg}$ resulted in significant

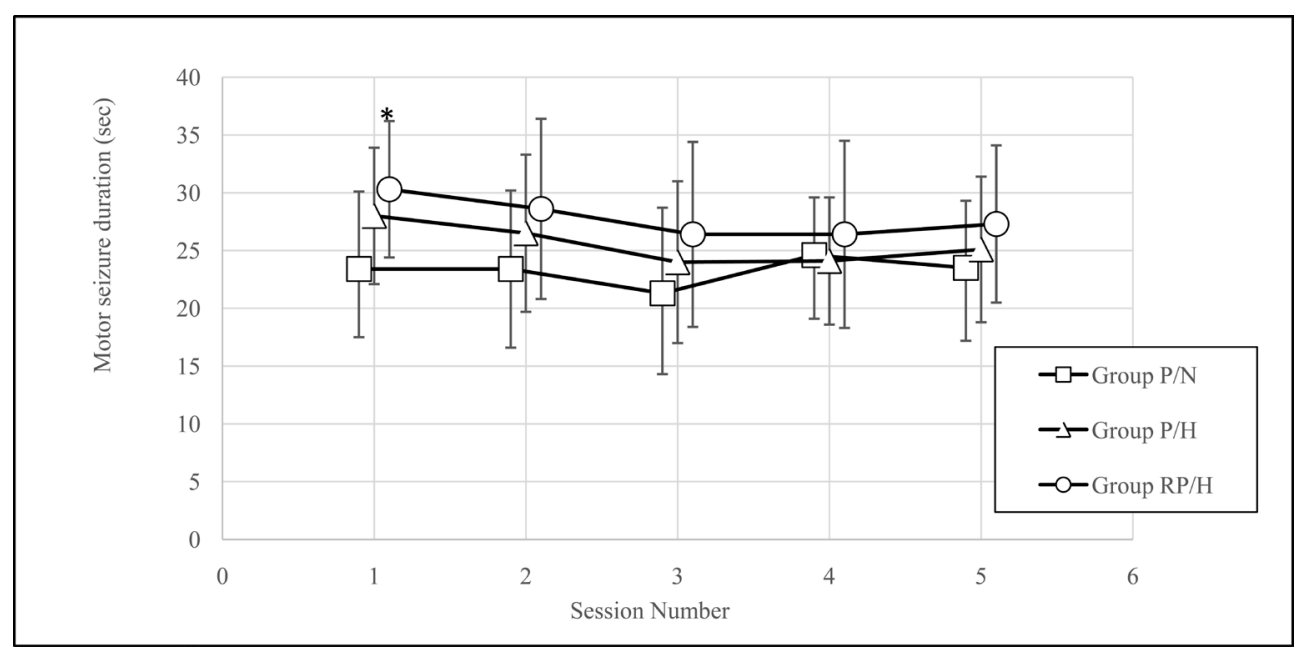

${ }^{*} \mathrm{P}<0.05$ in group RP/H compared with group P/N in the first ECT session. ECT: electroconvulsive therapy, Group P/N or P/H: normoventilated or hyperventilated group receiving a standard dose of propofol, Group RP/H: hyperventilated group receiving a reduced dose of propofol with remifentanil.

Figure 3. Motor seizure durations by session number in the three groups. Values are expressed as mean \pm SD.

Table 2. Comparative data of the three groups.

\begin{tabular}{|c|c|c|c|}
\hline & $\mathbf{P} / \mathbf{N}(\mathbf{n}=\mathbf{2 0})$ & $\mathbf{P} / \mathbf{H}(\mathbf{n}=\mathbf{2 0})$ & $\mathbf{R P} / \mathbf{H}(\mathbf{n}=\mathbf{2 0})$ \\
\hline No. of ECT sessions with motor seizure duration > $20 \mathrm{sec}(\%)$ & 75 & 83 & 86 \\
\hline No. of ECT sessions with EEG seizure duration > $25 \mathrm{sec}(\%)$ & 60 & 73 & $88^{*}$ \\
\hline No. of ECT sessions with peak RPP value > 20,000 (\%) & 15 & 17 & 21 \\
\hline Time to spontaneous breathing (min) & $3.1 \pm 1.0$ & $3.8 \pm 1.6$ & $6.5 \pm 2.5^{* *+\dagger}$ \\
\hline Emergence time (min) & $5.1 \pm 1.0$ & $5.9 \pm 1.6$ & $7.7 \pm 2.8^{* *+\dagger}$ \\
\hline Verapamil (mg) & $0.2 \pm 0.6$ & $0.3 \pm 0.7$ & $0.4 \pm 0.9$ \\
\hline Ephedrine (mg) & $1.3 \pm 2.7$ & $1.1 \pm 2.4$ & $2.1 \pm 3.0$ \\
\hline
\end{tabular}

ECT: electroconvulsive therapy, EEG: electroencephalogram, RPP: rate-pressure product; Values are expressed as means \pm SD or $n$. ${ }^{*} \mathrm{P}<0.05$ compared with group $\mathrm{P} / \mathrm{N} ;{ }^{* * *} \mathrm{P}<0.01$ compared with group $\mathrm{P} / \mathrm{N} ;{ }^{\dagger+} \mathrm{P}<0.05$ compared with group $\mathrm{P} / \mathrm{H}$. 
Table 3. Hemodynamic changes after the ECT stimulus in the three groups.

\begin{tabular}{lcccccc}
\hline & \multicolumn{3}{c}{ Increase for MAP baseline (\%) } & \multicolumn{3}{c}{ Increase for HR baseline (\%) } \\
\cline { 2 - 7 } & $\mathrm{P} / \mathrm{N}(\mathrm{n}=20)$ & $\mathrm{P} / \mathrm{H}(\mathrm{n}=20)$ & $\mathrm{RP} / \mathrm{H}(\mathrm{n}=20)$ & $\mathrm{P} / \mathrm{N}(\mathrm{n}=20)$ & $\mathrm{P} / \mathrm{H}(\mathrm{n}=20)$ & $\mathrm{RP} / \mathrm{H}(\mathrm{n}=20)$ \\
\hline ECT\#1 & $46.8 \pm 24.3$ & $45.3 \pm 24.4$ & $56.4 \pm 21.0$ & $42.1 \pm 28.7$ & $57.9 \pm 12.1$ & $61.6 \pm 17.5$ \\
ECT\#2 & $44.6 \pm 23.1$ & $47.0 \pm 22.3$ & $58.0 \pm 23.7$ & $45.7 \pm 20.9$ & $56.3 \pm 14.8$ & $62.5 \pm 16.6$ \\
ECT\#3 & $45.8 \pm 17.8$ & $46.6 \pm 16.7$ & $58.4 \pm 19.2$ & $48.8 \pm 20.7$ & $53.3 \pm 14.0$ & $56.3 \pm 18.8$ \\
ECT\#4 & $41.0 \pm 23.0$ & $45.3 \pm 22.3$ & $59.1 \pm 21.4$ & $45.8 \pm 11.9$ & $53.5 \pm 12.6$ & $57.3 \pm 20.6$ \\
ECT\#5 & $49.4 \pm 20.7$ & $50.8 \pm 17.1$ & $55.6 \pm 20.5$ & $50.2 \pm 19.7$ & $51.5 \pm 12.4$ & $52.6 \pm 18.9$ \\
\hline
\end{tabular}

ECT: electroconvulsive therapy, MAP: mean arterial blood pressure, HR: heart rate; Values are expressed as means \pm SD.

Table 4. Maximal value of RPP by session number in each group.

\begin{tabular}{cccc} 
& P/N (n= 20) & P/H (n= 20) & RP/H (n= 20) \\
\hline ECT\#1 & $13,552 \pm 4144$ & $13,916 \pm 6820$ & $13,435 \pm 4010$ \\
ECT\#2 & $14,871 \pm 3566$ & $14,402 \pm 6955$ & $15,124 \pm 6238$ \\
ECT\#3 & $13,218 \pm 5741$ & $14,745 \pm 6833$ & $15,863 \pm 5577$ \\
ECT\#4 & $13,570 \pm 4610$ & $15,951 \pm 5385$ & $15,695 \pm 4223$ \\
ECT\#5 & $13,288 \pm 4781$ & $15,220 \pm 5995$ & 4899 \\
\hline
\end{tabular}

ECT: electroconvulsive therapy, RPP: rate-pressure product; Values are expressed as means \pm SD.

prolongations of both EEG seizure durations in the first and second sessions and motor seizure duration in the first session and a larger number of ECT sessions with EEG seizure duration of more than 25 sec compared to the use of a standard dose of propofol alone, with a significant reduction in the electrical requirement during ECT. In addition, it produced no significant differences in hemodynamic changes after ECT compared with the use of standard dose of propofol with or without moderate hyperventilation.

A favorable clinical outcome of ECT has been reported to depend on the production of adequate therapeutic seizures. Although propofol has a major disadvantage in that it is an anticonvulsant and decreases seizure duration in a dose-dependent fashion, several studies decreasing the dosage of propofol by addition of remifentanil [11]-[14] have demonstrated a significant prolongation of duration of seizure activities. Moreover, severe acute hyperdynamic responses to ECT caused by reducing the standard dose of propofol could have been attenuated to an acceptable outcome by the additional injection of remifentanil immediately before ECT in our previous study [14]. In the present study, with the aim of more seizure augmentation and/or fewer side effects, the efficacy and safety of the concurrent use of moderate hyperventilation and a reduced dose of propofol combined with divided remifentanil in ECT practice were evaluated.

Patients undergoing ECT commonly have gradual increases in electrical stimulus intensities to produce a seizure with an increasing number of ECT treatments, and higher stimulus intensities are likely to cause increased levels of cognitive impairment [20]. In the present study, however, the incidences of cognitive side effects were not significantly different among the three groups despite significant differences in stimulus doses.

Regarding the relationship between hyperventilation and seizure duration in ECT, Chater et al. [7] and Pande et al. [8] demonstrated a correlation between excessive hyperventilation-induced severe hypocapnia $\left(\mathrm{ETCO}_{2}: 20\right.$ - $27 \mathrm{mmHg}$ ) prior to ECT and seizure duration in the early phase of ECT practice. However, since it is difficult to safely use these methods, Sawayama et al. [9] used moderate hypocapnia $\left(\mathrm{ETCO}_{2}: 30 \mathrm{mmHg}\right)$ by moderate hyperventilation and found that there was a significant prolongation of the duration of EEG seizures, but not of motor seizures. They suggested that lower levels of hyperventilation and/or stimulus intensity were the reason for failure in motor seizure prolongation. In the present study with the half-age stimulation setting, enhancing effects of moderate hyperventilation $\left(\mathrm{ETCO}_{2}: 30-35 \mathrm{mmHg}\right)$ on ECT-induced seizure activities were also observed only in EEG seizures, while the combination of moderate hyperventilation and the use of a reduced dose of propofol led to significant increases in both durations of EEG and motor seizures, without higher electrical stimulus intensities. The proposed explanation for this observation was that a decrease in seizure thresholds due to the reduction of propofol dosage by anesthetic-sparing effects of remifentanil might have facilitated more augmentation of moderate hyperventilation-mediated enhancement of seizure activities. However, these effects 
did not appear to be sustained, as was also observed in the present study, and therefore other augmentation techniques are necessary to maintain seizure quality.

As adverse effects associated with hyperventilation, Bergsholm et al. [21] found that hypocapnia induced by hyperventilation markedly augmented the ECT-induced increase in HR and RPP. In the present study, although the percentages of $\Delta \mathrm{HR}$ for the baseline and peak RPP values tended to be greater in groups $\mathrm{P} / \mathrm{H}$ and $\mathrm{RP} / \mathrm{H}$ than in group $\mathrm{P} / \mathrm{N}$ in each session, there were no significant differences among the three groups. For these reasons, first, the use of lower levels of hypocapnia $\left(\mathrm{ETCO}_{2} 30-35 \mathrm{mmHg}\right.$ ) in groups $\mathrm{P} / \mathrm{H}$ and $\mathrm{RP} / \mathrm{H}$ compared with the severe levels $\left(\mathrm{ETCO}_{2}\right.$ of $\left.14 \mathrm{mmHg}\right)$ used in the above study might have blunted the increase in $\mathrm{HR}$ after the ECT stimulus. Second, no significant difference between groups $\mathrm{P} / \mathrm{N}$ and $\mathrm{P} / \mathrm{H}$ was detected in the increase in SBP after ECT, which was consistent with the report by Bergsholm et al. [21] that hyperventilation did not cause an increase in BP. Third, although a high electrical dosage has been reported to result in marked hemodynamic lability [22], the stimulus intensity required in group $\mathrm{RP} / \mathrm{H}$ was close to or lower than in groups $\mathrm{P} / \mathrm{N}$ and $\mathrm{P} / \mathrm{H}$ in each session in this study. Considering these findings, patients in group RP/H might have had no significant increase in RPP compared with those in groups P/N and P/H because of similar rises in SBP and HR after ECT. In general, although augmented interventions associated with longer seizures have been reported to have longer emergence times [23] [24], a similar tendency was found in the present study. Delayed emergence from anesthesia also appeared to be greatly related to the use of remifentanil rather than to moderate hyperventilation in the present study.

As for positioning of electrodes, unilateral ECT has been reported to cause less severe cognitive side effects, though an electrical dosage $500 \%$ above the seizure threshold is needed for efficacy equivalent to that of bilateral ECT, and such a high electrical dosage would be associated with marked hemodynamic lability [22]. In the current study, the aim of which was to determine an acceptable augmenting strategy for patients responding poorly to standard ECT treatment, bilateral ECT was thus used for electrode placement.

One limitation of the present study was the inability to record continuous blood pressure readings due to the required cycling time of the blood pressure cuff; thus, the highest value after ECT stimulus may have been overlooked.

\section{Conclusion}

Concurrent application of a reduced dose of propofol combined with divided supplemental remifentanil and moderate hyperventilation for ECT procedures would offer advantages over the use of a standard dose of propofol with or without moderate hyperventilation in terms of a significant prolongation of seizure duration in the early phase and a significant reduction in the electrical requirement in the late phase during the ECT course.

\section{Competing Interest}

The authors have no conflicts of interest to declare, financial or otherwise.

\section{References}

[1] American Psychiatric Association (2001) The Practice of Electroconvulsive Therapy: Recommendations for Treatment, Training and Privileging. American Psychiatric Press Inc., Washington DC.

[2] Colanda, C.C. and McDall, M.V. (1996) A Statistical Model Predicting the Seizure Threshold for Right Unilateral ECT in 106 Patients. Convulsive Therapy, 12, 3-12.

[3] Sackeim, H.A., Devanand, D.P. and Prodic, J. (1991) Stimulus Intensity, Seizure Threshold, and Seizureduration: Impact on the Efficacy and Safety of Electroconvulsive Therapy. Psychiatric Clinics of North America, 14, 803-843.

[4] Avramov, M.N., Husain, M.M. and White, P.F. (1995) The Comparative Effects of Methohexital, Propofol, and Etomidate for Electroconvulsive Therapy. Anesthesia and Analgesia, 81, 596-602.

[5] Ding, Z. and White, P.F. (2002) Anesthesia for Electroconvulsive Therapy. Anesthesia and Analgesia, 94, $1351-1364$. http://dx.doi.org/10.1097/00000539-200205000-00057

[6] Loo, C., Simpson, B. and MacPherson, R. (2010) Augmentation Strategies in Electroconvulsive Therapy. The Journal of ECT, 26, 202-207. http://dx.doi.org/10.1097/YCT.0b013e3181e48143

[7] Chater, S.N. and Simpson, K.H. (1988) Effect of Passive Hyperventilation on Seizure Duration in Patients Undergoing Electroconvulsive Therapy. British Journal of Anaesthesia, 60, 70-73. http://dx.doi.org/10.1093/bja/60.1.70 
[8] Pande, A.C., Shea, J., Shettar, S., Grunhaus, L.J. and Haskett, R.F. (1990) Effect of Hyperventilation Onseizure Length during Electroconvulsive Therapy. Biological Psychiatry, 27, 799-801. http://dx.doi.org/10.1016/0006-3223(90)90597-U

[9] Sawayama, E., Takahashi, M., Inoue, A., Nakajima, K., Kano, A., Sawayama, T., Okutomi, T. and Miyaoka, H. (2008) Moderate Hyperventilation Prolongs Electroencephalogram Seizure Duration of the First Electroconvulsive Therapy. The Journal of ECT, 24, 195-198. http://dx.doi.org/10.1097/YCT.0b013e3181620815

[10] Recart, A., Rawal, S., White, P.F., Byerly, S. and Thornton, L. (2003) The Effect of Remifentanil on Seizure Duration and Acute Hemodynamic Responses to Electroconvulsive Therapy. Anesthesia and Analgesia, 96, 1047-1050. http://dx.doi.org/10.1213/01.ANE.0000054002.65040.B3

[11] Vishne, T., Aronov, S., Amiaz, R., Etchin, A. and Grunhaus, L. (2005) Remifentanil Supplementation of Propofol during Electroconvulsive Therapy. The Journal of ECT, 21, 235-238. http://dx.doi.org/10.1097/01.yct.0000180040.06338.ac

[12] Porter, R., Booth, D., Gray, H. and Frampton, C. (2008) Effects of the Addition of Remifentanil to Propofol Anesthesia on Seizure Length and Postictal Suppression Index in Electroconvulsive Therapy. The Journal of ECT, 24, 203-207. http://dx.doi.org/10.1097/YCT.0b013e3181662ca0

[13] Chen, S.T. (2011) Remifentanil: A Review of Its Use in Electroconvulsive Therapy. The Journal of ECT, 27, $323-327$. http://dx.doi.org/10.1097/YCT.0b013e31821072d2

[14] Nishikawa, K., Higuchi, M., Kawagishi, T., Shimodate, Y. and Yamakage, M. (2011) Effect of Divided Supplementation of Remifentanil on Seizure Duration and Hemodynamic Responses during Electroconvulsive Therapy under Propofol Anesthesia. Journal of Anesthesia, 25, 29-33. http://dx.doi.org/10.1007/s00540-010-1049-4

[15] Abdallah, C.G., Fasula, M., Kelmendi, B., Sanacora, G. and Ostroff, R. (2012) The Rapid Antidepressant Effect of Ketamine in the Electroconvulsive Therapy Setting. The Journal of ECT, 28, 157-161. http://dx.doi.org/10.1097/YCT.0b013e31824f8296

[16] Rasmussen, K.G., Kung, S., Lapid, M.I., Oesterle, T.S., Geske, J.R., Nuttall, G.A., Oliver, W.C. and Abenstein, J.P. (2014) A Randomized Comparison of Ketamine versus Methohexital Anesthesia in Electroconvulsive Therapy. Psychiatry Research, 215, 362-365. http://dx.doi.org/10.1016/j.psychres.2013.12.027

[17] Petrides, G. and Fink, M. (1996) The “Half-Age” Stimulation Strategy for ECT Dosing. Convulsive Therapy, 12, 138-146.

[18] Bayer, J.L., Weiner, R.D. and Glenn, M.D. (1998) Electroconvulsive Therapy: A Programmed Text, 2nd Edition, American Psychiatric Press Inc., Washington DC.

[19] Anderson, F.A., Arsland, D. and Holst-Larsen, H. (2001) Effects of Combined Methohexitone-Remifentanil Anesthesia in Electroconvulsive Therapy. Acta Anaesthesiologica Scandinavica, 45, 830-833. http://dx.doi.org/10.1034/j.1399-6576.2001.045007830.x

[20] Sackeim, H.A., Prudic, J., Devavand, D.P., Kiersky, J.E., Fitzsimons, L., Moody, B.J., McElhiney, M.C., Coleman, E.A. and Settembrino, J.M. (1993) Effects of Stimulus Intensity and Electrode Placement on the Efficacy and Cognitive Effects of Electroconvulsive Therapy. The New England Journal of Medicine, 328, 839-846. http://dx.doi.org/10.1056/NEJM199303253281204

[21] Bergsholm, P., Bleie, H., Gran, L. and d’Elia, G. (1993) Cardiovascular Response and Seizure Duration as Determined by Electroencephalography during Unilateral Electroconvulsive Therapy. Acta Psychiatrica Scandinavica, 88, 25-28. http://dx.doi.org/10.1111/j.1600-0447.1993.tb03409.x

[22] Sackeim, H.A., Prudic, J., Devanand, D.P., Nobler, M.S., Lisanby, S.H., Peyser, S., Fitzsimons, L., Moody, B.J. and Clark, J. (2000) A Prospective, Randomized, Double-Blind Comparison of Bilateral and Right Unilateral Electroconvulsive Therapy at Different Stimulus Intensities. Archives of General Psychiatry, 57, 425-434. http://dx.doi.org/10.1001/archpsyc.57.5.425

[23] Akcaboy, Z.N., Akcaboy, E.Y., Yigitbasi, B., Bayam, G., Dikmen, B., Gogus, N. and Dilbaz, N. (2005) Effects of Remifentanil and Alfentanil on Seizure Duration, Stimulus Amplitudes and Recovery Parameters during ECT. Acta Anaesthesiologica Scandinavica, 49, 1068-1071. http://dx.doi.org/10.1111/j.1399-6576.2005.00766.x

[24] Hooten, W.M. and Rasmussen, K.G. (2008) Effects of General Anesthetic Agents in Adults Receiving Electroconvulsive Therapy: A Systematic Review. The Journal of ECT, 24, 208-223. http://dx.doi.org/10.1097/YCT.0b013e31815bfe2a 